\title{
À propos de quelques outils de collecte de données : réflexions sur les pratiques numériques
} en archéologie

About Some Data Collection Tools: Reflections on Digital Practices in Archaeology

Christophe Tufféry, Vincent Delvigne, Paul Fernandes et Céline BressyLéandri

\section{(2) OpenEdition Journals}

Édition électronique

URL : https://journals.openedition.org/revuehn/1603

DOI : 10.4000/revuehn. 1603

ISSN : 2736-2337

Éditeur

Humanistica

\section{Référence électronique}

Christophe Tufféry, Vincent Delvigne, Paul Fernandes et Céline Bressy-Léandri, «À propos de quelques outils de collecte de données : réflexions sur les pratiques numériques en archéologie », Humanités numériques [En ligne], 3 | 2021, mis en ligne le 01 mai 2021, consulté le 16 juillet 2021. URL : http:// journals.openedition.org/revuehn/1603 ; DOI : https://doi.org/10.4000/revuehn.1603

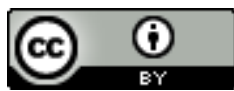

Les contenus de la revue Humanités numériques sont mis à disposition selon les termes de la Licence Creative Commons Attribution 4.0 International. 


\title{
humanités numériques
}

$3 \mid 2021$

Humanités numériques spatialisées

SYSTĖMES D'INFORMATION GÉOGRAPHIQUE ET ARCHÉOLOGIE

\section{À propos de quelques outils de collecte de données : réflexions sur les pratiques numériques en archéologie}

\section{About Some Data Collection Tools: Reflections on Digital Practices in Archaeology}

\author{
Christophe Tufféry, Vincent Delvigne, Paul Fernandes et \\ Céline Bressy-Léandri
}

\section{Résumés}

Depuis 2006, plusieurs projets collectifs de recherche (PCR) « Réseau de lithothèques ", fédérés depuis 2019 dans le cadre d'un groupement de recherche (GDR), procèdent au recueil d'importants volumes de données spatialisées sur les silicites en France métropolitaine. Un inventaire exhaustif et harmonisé des lithothèques sur ces matériaux est également en cours. Divers dispositifs techniques numériques ont été utilisés pour la production, la mise en commun, l'analyse, le partage et la restitution de données spatiales : dessin assisté par ordinateur, systèmes d'information géographique, systèmes de gestion de bases de données, plateformes de partage et de publication de données, applications nomades. $\mathrm{Au}$ fur et à mesure de la mise en œuvre de ces outils, des questionnements méthodologiques et épistémologiques sont survenus. Ils concernent notamment la conception et la mise en œuvre de ces dispositifs pour des chercheurs d'horizons disciplinaires différents (archéologie, préhistoire, géographie, pétrographie, minéralogie, géochimie, etc.) dont les pratiques sont modifiées, à des degrés divers, par les conditions et les contextes de mise en pratique des dispositifs numériques.

Since 2006, several Collective Research Projects (PCR) entitled "Réseau de lithothèques" - which have been grouped together as part of a Research Group (GDR) since 2019 - have been collecting large volumes of spatial data on sedimentary silicified rocks (SSR) in France. An exhaus- 
tive and harmonised inventory of rock libraries containing these materials is also in progress. Several digital devices have been used for producing, pooling, analysing, sharing and rendering these spatial data: computer-aided drawing, geographic information systems, database management systems, data sharing and publication platforms, mobile applications. During the implementation of these tools, methodological and epistemological questions arose. They concern the design and implementation of such devices for researchers from heterogeneous disciplinary horizons (archaeology, prehistory, geography, petrography, mineralogy, geochemistry, etc.); their practices are modified, to a variable extent, by the conditions and contexts in which these digital devices are implemented.

\section{Entrées d'index}

MOTS-CLÉS : humanités numériques spatialisées, base de données, archéologie, collecte de données, cartographie en ligne, système d'information géographique, épistémologie

KEYWORDS: spatial digital humanities, database, archaeology, webmapping, data gathering, geographic information system, epistemology

\section{Introduction : éléments généraux sur l'inventaire et la caractérisation des silicites}

La caractérisation pétrologique des matériaux utilisés par les populations préhistoriques est aussi ancienne que l'archéologie préhistorique elle-même (par exemple, Meillet 1866 ; Boule 1887 ; Hue 1929 ; Hewitt 1915). Au cours des années 2000, plusieurs bases de données ont été mises en œuvre dans ce domaine de recherche : par P. Depaepe dans la vallée de la Vanne (Depaepe 2002), par J. Fabre et A. Lamotte dans la vallée de la Somme (Fabre, Lamotte et Antoine 2002, 2003 ; Lamotte et Fabre 2007), par P. Allard dans le nord-est de la France et de la Belgique (Allard 2003), par B. Huet dans le Massif armoricain (Huet 2006 ; Huet et al. 2003), par S. Grégoire et F. Bazile en Occitanie (Grégoire et Bazile 2005), par J. Detrey et T. Rebmann dans les Vosges (Detrey et Rebmann 2004), par M.-H. Moncel, J.-P. Raynal et C. Bressy dans le couloir rhodanien (Moncel 2008 ; Bressy 2006), ou par Jaccottey et Milleville dans le Jura (Jaccottey et Milleville 2009). Dans la plupart des cas, ces bases de données correspondaient à des recherches limitées géographiquement, selon des critères propres et non harmonisées qui ne permettaient pas de croiser les données, ni de les interroger ensemble.

Tous ces travaux ont pour dénominateur commun la volonté de mieux connaître le potentiel minéral, afin de comprendre la gestion des espaces par les collectifs préhistoriques. Pour autant la limitation géographique induite par le découpage administratif des programmes de recherche n'a pas favorisé la mise en évidence de circulation de maté- 
riaux transrégionaux et il semble qu'aucune réflexion de fond sur la valeur intrinsèque des données acquises n'ait eu lieu à ces occasions : problème du transfert actualiste ; partialité des jeux de données, évolution des matériaux, etc. Ainsi, à l'exception de la reconnaissance de quelques matériaux marqueurs - pour le préhistorien - (silex du Bergeracois, du Grand-Pressigny, du Fumelois...), les diagnoses pétrologiques se sont fondées sur les connaissances empiriques de quelques spécialistes, mais sans pour autant que le partage de données interindividuel ne soit rendu possible. Le développement des outils de partage de données, que ce soit des bases de données en ligne ou des systèmes d'information géographique (SIG) partagés, permettent aujourd'hui de dépasser ce biais, mais seulement et seulement si tous les acteurs qui font aujourd'hui de la pétroarchéologie s'approprient ces outils dans leur pratique, mais en comprenant les limites et les possibilités de chacun d'eux.

Aujourd'hui, l'étude de la provenance des géoressources, dont les silicites (silex, chert, silcrètes et silice hydrothermale), s'inscrit en effet dans un ensemble d'analyses pluridisciplinaires mobilisant un grand nombre de spécialistes de différentes disciplines qui ont besoin de parler un langage commun et d'utiliser des outils adaptés à tous. Les recherches portent ainsi sur les conditions d'exploitation des paléoenvironnements, la géologie, la géomorphologie, la pédologie, la structure et la gestion anthropique des espaces géographiques ou encore sur les conditions d'extraction, d'utilisation et d'abandon des matériaux lithiques par les populations préhistoriques. Or, depuis une quinzaine d'années, d'importantes avancées ont contribué à la caractérisation pétrologique des silicites et l'identification des marqueurs minéralogiques traduisant les étapes de leur parcours post-génétique. Ces travaux sont à la base de la notion de " chaîne évolutive " (Fernandes 2006, 2012 ; Fernandes et Raynal 2006 ; Thiry et al. 2014 ; Delvigne 2016, 2019 ; Delvigne et al. 2018) qui s'appuie sur la prise en compte de la double dimension spatiale et temporelle des divers processus intervenant dans l'évolution des géomatériaux selon qu'ils se trouvent dans des gîtes primaires (affleurements dans les formations géologiques d'origine) ou des gîtes secondaires (ex : colluvions, alluvions en fonds de vallées, cordons marins...). Ces études mobilisant de nombreuses techniques d'observation optique, de l'échelle macroscopique à l'échelle ultramicroscopique (microscope optique et microscope électronique à balayage, etc.), nécessitent des compétences et des capacités d'expertise de haut niveau dans divers domaines des sciences naturelles. Si la prise en compte de la chaîne évolutive a de réels impacts sur les modèles de gestion de l'espace en préhistoire (Fernandes et al. 2007 ; Delvigne 2016 ; Delvigne et al. 2020), elle se répercute également sur toute la chaîne de traitement de données, de la collecte des échantillons géologiques à la constitution des lithothèques en passant par la visualisation et le traitement des données spatiales. C'est à cette double perspective d'évolution des pratiques partage des données à grande échelle et renouveau méthodologique qu'est aujourd'hui confrontée la pétroarchéologie, entraînant la mise en place de nouveaux outils, de nouveaux protocoles et de nouveaux paradigmes. 
Dans cet article, nous illustrerons notre propos par l'exemple des applications de collecte des données développées ces 15 dernières années en pétroarchéologie, en cherchant dans une seconde partie à inscrire ce développement dans un cadre plus large qui intéresse les changements de pratiques en archéologie sous l'impulsion du numérique.

\section{Les travaux des PCR « Réseau de lithothèques " et du GDR SILEX}

Depuis 2006, plusieurs projets collectifs de recherche (PCR) - dont l'inventaire et la cartographie des formations à silicites forment un des axes principaux - sont cofinancés par le ministère de la Culture, les collectivités territoriales, le CNRS, l'Institut national de recherches archéologiques préventives (INRAP) et la société Paléotime. D’abord développés localement par des solutions non partagées de dessin assisté par ordinateur (DAO) ou de SIG (figure 1), ces projets ont rapidement cherché à harmoniser leurs protocoles afin de discuter avec un langage commun (au sens numérique du terme).

FIGURE 1. EXEMPLES DE CARTES NON PARTAGÉES DES FORMATIONS À SILICITES
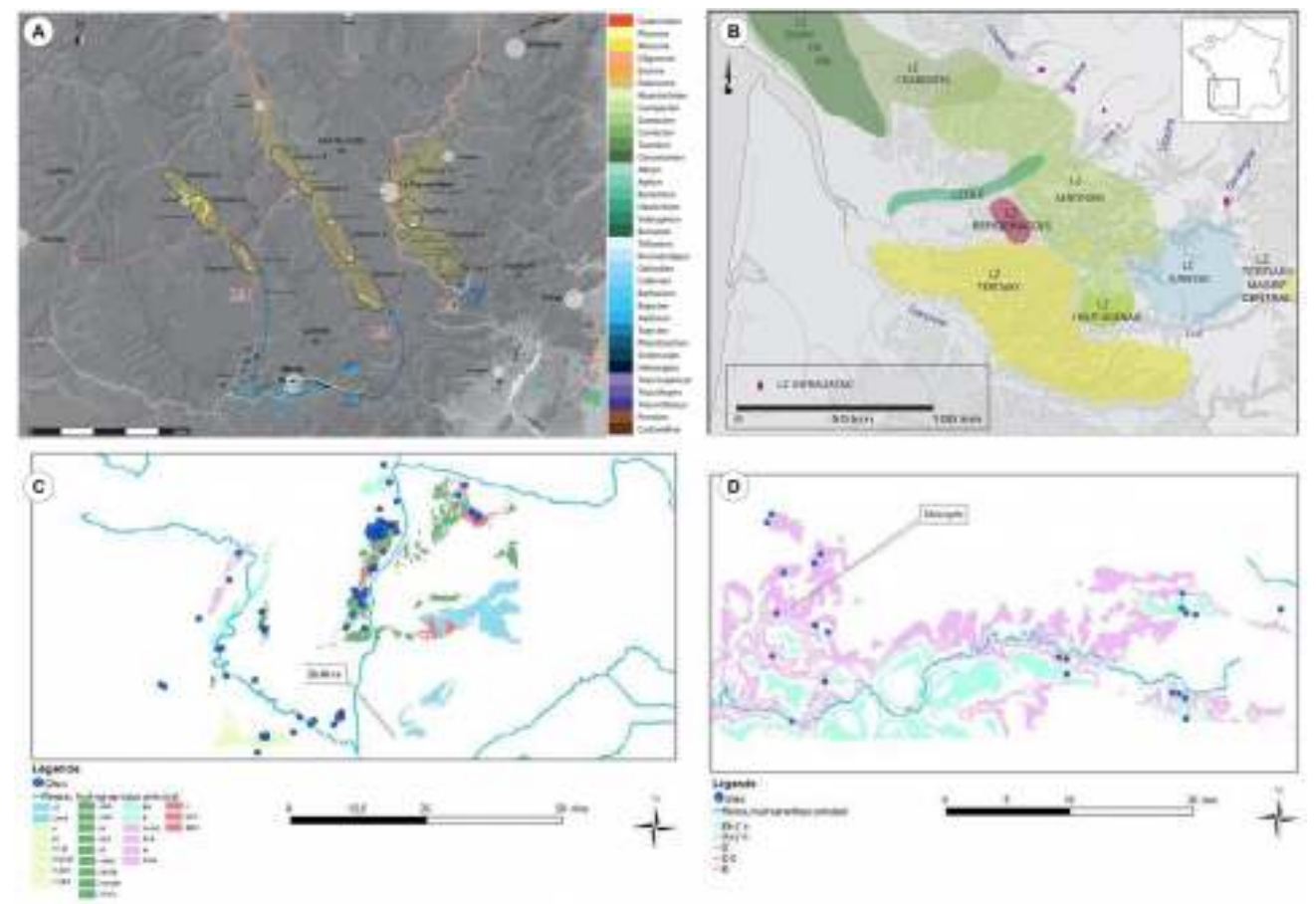

Images produites par les auteurs - A : Fernandes 2012 ; B : Turq et al. 2017 ; C et D : Fernandes et Tufféry 2005

Une méthode harmonisée pour la numérisation des contours cartographiques des formations siliceuses a ainsi été mise au point, mais le protocole de numérisation - très lourd - n'avait jusqu'alors pas permis de pleinement répondre aux attentes des chercheurs. Elle a été utilisée ponctuellement pour la numérisation de formations concernées dans les territoires couverts par les divers PCR : Auvergne-Rhône-Alpes (Fernandes 2019), Nouvelle-Aquitaine (Turq 2019), Centre-Val de Loire (Delvigne 2019) et Île-de-France (Allard 2019). Cette méthode s'appuie à la fois sur l'analyse des données de terrain (observations, échantillonnages) et sur la lecture critique des cartes géologiques à l'échelle 1/50 ooo 
du Bureau de recherches géologiques et minières (BRGM) pour constituer une base de données spatiales (Fernandes et al. 2013, 2016). Pour chaque région concernée, la numérisation des contours des formations contenant des silicites a été validée par un expert, ayant une très bonne connaissance des formations. Des vérifications sur le terrain ont été - et sont encore - nécessaires pour vérifier certains contours ou lever des doutes d'attribution géologique. Ces vérifications sont faites au moyen de formulaires adaptés dont les données saisies sur le terrain sont intégrées sous la forme d'une couche de points dans le SIG, après validation (voir figure 4).

Suite à ces résultats obtenus par les quatre PCR et devant le constat de la nécessité de fédérer ces initiatives régionales à un échelon national, est apparue la volonté d'associer ces travaux en un groupement de recherche (GDR) baptisé GDR « SILEX ». Il bénéficie de financements sur cinq années (2019-2023) du ministère de la Culture, de deux instituts du CNRS (INEE et INSHS), de l'INRAP et de la société Paléotime.

Depuis 2019, de nouvelles données géoréférencées sont proposées en téléchargement gratuit. Ce sont des données de la base de données harmonisée Bd Charm-50, issues de la numérisation des cartes géologiques départementales au 1/50 ooo du BRGM ${ }^{1}$. Ces couches de données sont disponibles au format vectoriel shapefile (SHP) et peuvent être téléchargées par département. Ces données viennent considérablement aider le travail d'inventaire des formations géologiques à silicites entrepris par les PCR, puisque les contours numérisés des formations sont déjà disponibles. Les données comportent aussi des informations descriptives par formations géologiques et non par époque, ce qui permet d'extraire aisément dans un logiciel de SIG les données concernant les formations à silicites utiles à nos travaux. Le travail de référencement des gîtes à silicites se fait à l'échelle de la formation puisqu'à de rares exceptions près, la définition d'un type gîtologique ${ }^{2}$ nécessite la prise en compte de toutes les observations faites sur du matériel issu d'une même formation et non pas des informations d'un gîte pris isolément. À titre d'exemple, en moins de deux mois, l'ensemble des données ont pu être traitées par deux d'entre nous (V. Delvigne et C. Tufféry) pour les 90 cartes au 1/50 ooo de la région Centre-Val de Loire et ses territoires limitrophes, soit une surface d'environ $50000 \mathrm{~km}^{2}$.

\section{Une application pour la saisie en mobilité des données de terrain et une solution de cartographie en ligne pour leur partage et leur publication}

Depuis 2018, une application utilisable sur le terrain a été développée pour saisir les données pendant les campagnes de prospection vérifiant les contours des formations présentes dans le SIG. Elle a été développée avec la solution ArcGIS Survey123 de la société américaine Environmental Systems Research Institute (ESRI ${ }^{3}$ ) et fonctionne sur divers supports et systèmes d'exploitation (smartphones et tablettes sous Android et iOS), connectés ou non à l'Internet mobile (figure 2). 

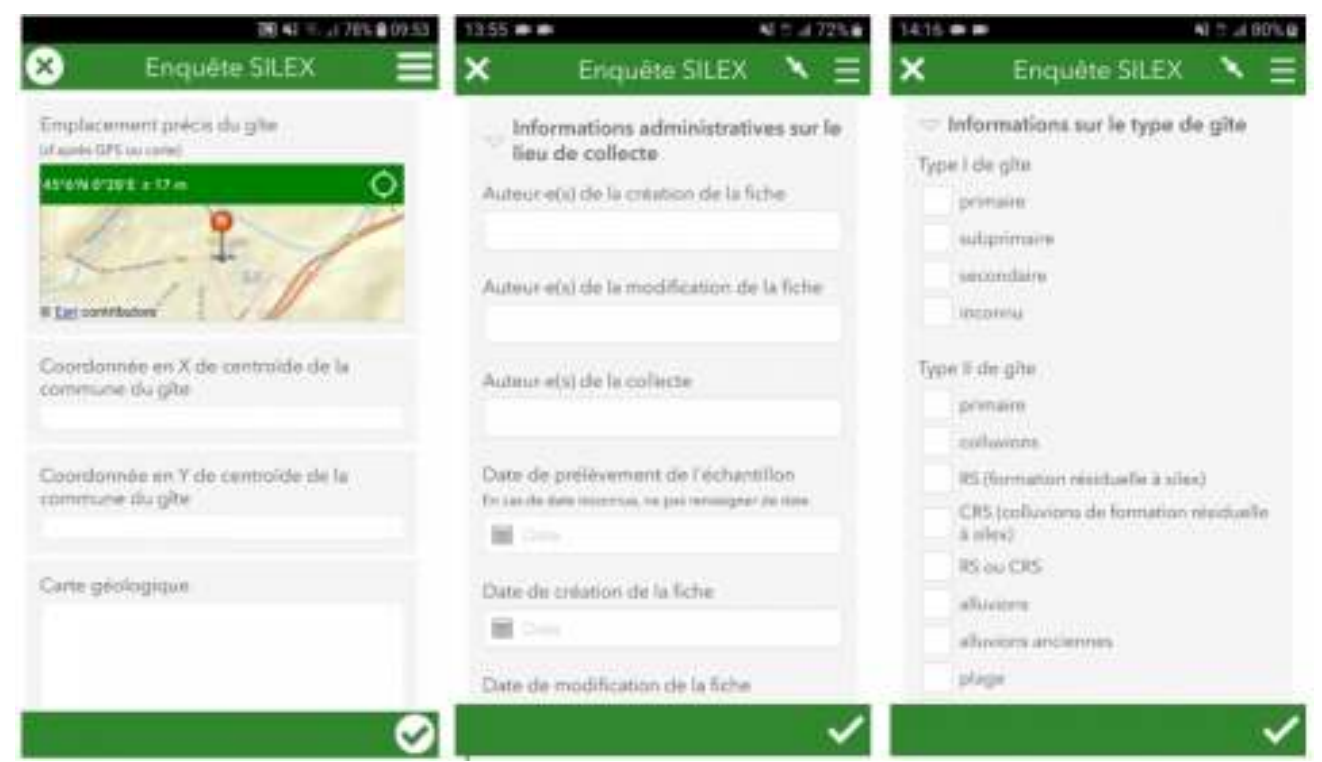

Images produites par les auteurs · Fond de la vignette cartographique : (C) ESRI contributors

Une application Web permet de consulter les données, de les compléter, de les corriger, de les exporter dans divers formats et de les partager (figure 3).

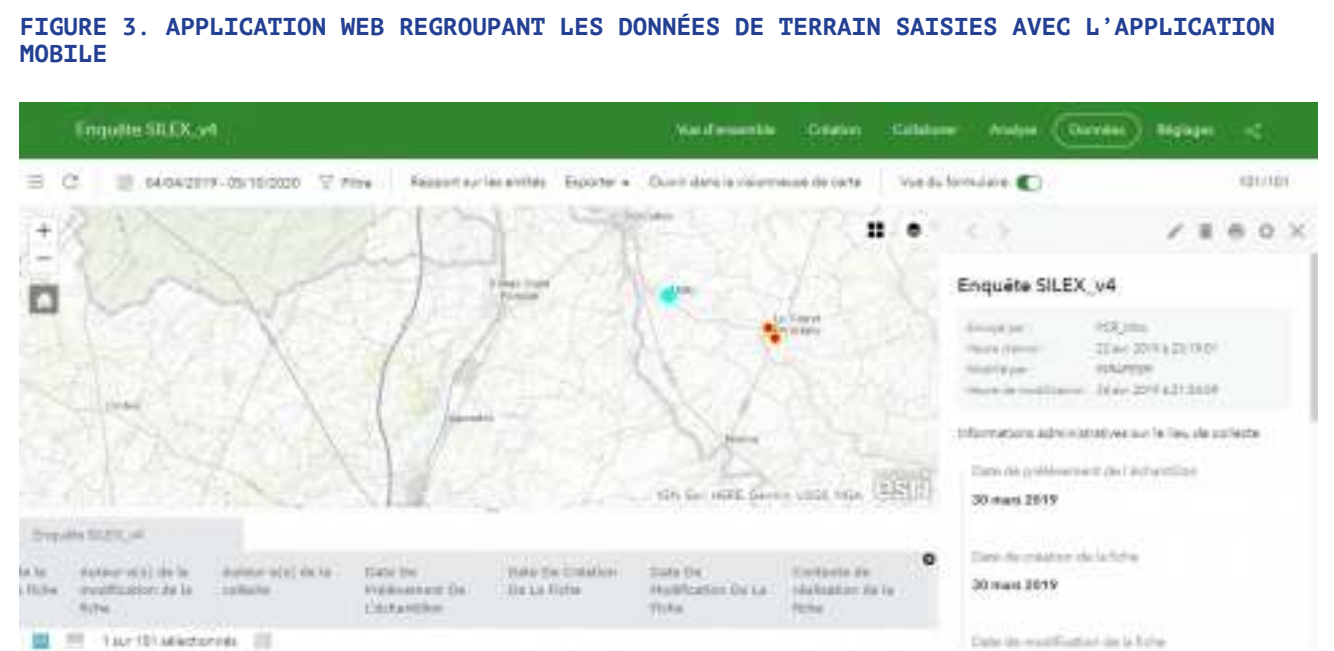

Image produite par les auteurs · Fond cartographique : (C) ESRI HERE Garmin, FAO, USGS, NOAA

Les données d'observation enregistrées sur le terrain peuvent être, soit synchronisées aussitôt sur un serveur distant par une connexion à l'Internet mobile, soit sauvegardées sur le dispositif de l'utilisateur et synchronisées ultérieurement.

En complément de cet outil, une application de cartographie en ligne (webmapping) a été développée sur la plateforme cartographique ArcGIS Online (AGOL) d'ESRI ${ }^{4}$ à l'aide de l'outil ArcGIS Web AppBuilder ${ }^{5}$ (Tufféry et al. 2019) (figure 4). Cette application permet de regrouper les données de terrain issues de l'application mobile et celles provenant des inventaires de lithothèques. 


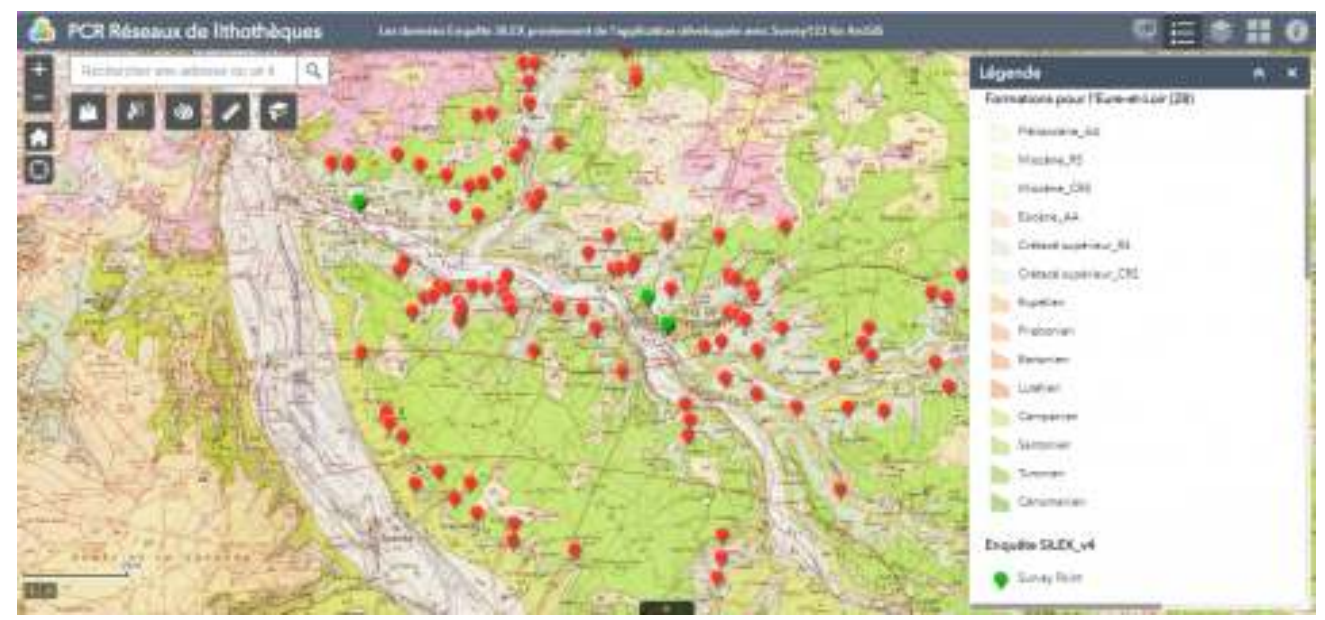

Image produite par les auteurs · Fond cartographique : Infoterre (c) BRGM

L'application permet aussi d'afficher et d'interroger les données spatiales et les contours des formations géologiques provenant du BRGM. Toutes les données sont disponibles en téléchargement dans divers formats (CSV, KML, SHP, etc.). L'application peut aussi afficher les flux de données cartographiques WMS comme celui du BRGM sur les cartes géologiques scannées ${ }^{6}$. Si les métadonnées des données géoréférencées peuvent être saisies dans AGOL selon la norme INSPIRE ISO 19115, il a été fait le choix pour l'instant d'opter pour une autre norme, l'ISO 15836, dite Dublin Core, qui se limite à une quinzaine de descripteurs ${ }^{7}$. Certaines des métadonnées peuvent apparaître dans la fiche descriptive des lieux de collecte d'un échantillon géologique sur le terrain (vert) ou d'un gîte décrit dans une lithothèque (rouge) (figure 5).

FIGURE 5. AFFICHAGE DES DONNÉES ET MÉTADONNÉES ASSOCIÉES À L'UN DES LIEUX DE COLLECTE D’UN ÉCHANTILLON GÉOLOGIQUE DÉCRIT DANS UNE LITHOTHĖQUE (POINTS ROUGES)

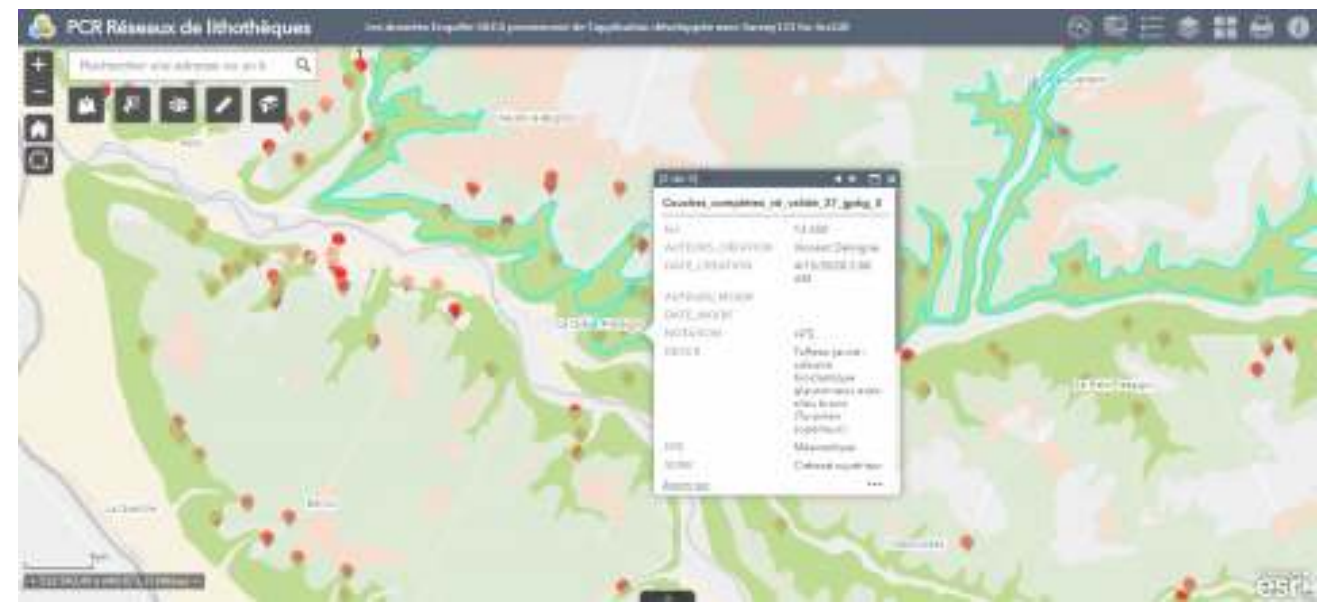

Image produite par les auteurs : travaux du PCR « Réseau de lithothèques » en région Centre-Val de Loire · Fond cartographique : (C) ESRI HERE Garmin, FAO, USGS, NOAA

Toutes les données disponibles dans cette application cartographique sont accessibles depuis un navigateur Web mais aussi avec d'autres applications mobiles proposées par ESRI, comme ArcGIS Explorer ${ }^{8}$. Cette dernière application permet de naviguer cartographiquement, de sélectionner des données, d'afficher les couches de son choix et d'ajouter des annotations (figure 6). 

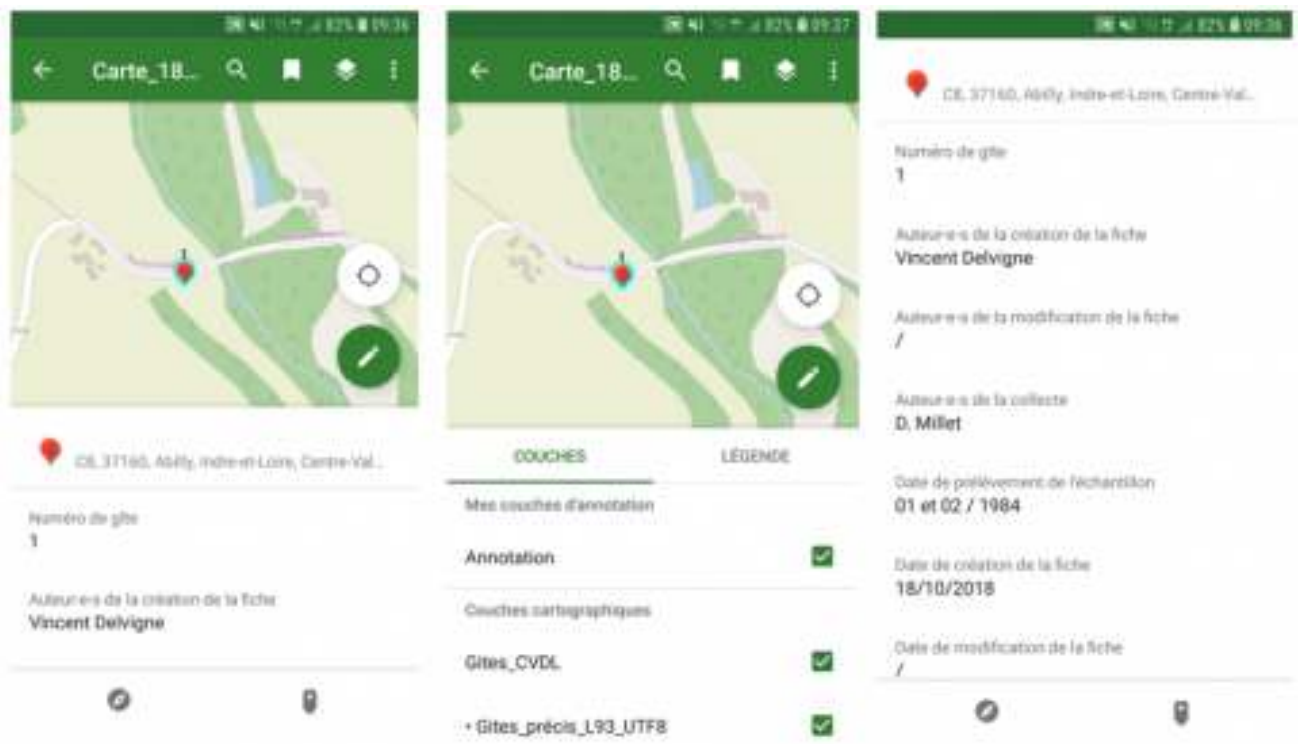

Images produites par les auteurs $\cdot$ Fond de la vignette cartographique : (c ESRI contributors

Cette application permet également de consulter d'autres ressources associées aux points, par exemple les photos d'un lieu de prélèvement ou d'un échantillon (figure 7).

FIGURE 7. ÉCRANS DE L'APPLICATION MOBILE ARCGIS EXPLORER PERMETTANT LA CONSULTATION DES PHOTOS ASSOCIÉES AUX DONNÉES D'UN LIEU DE PRÉLĖVEMENT, D'UN ÉCHANTILLON OU D'UN GÎTE DÉCRIT DANS UNE LITHOTHĖQUE
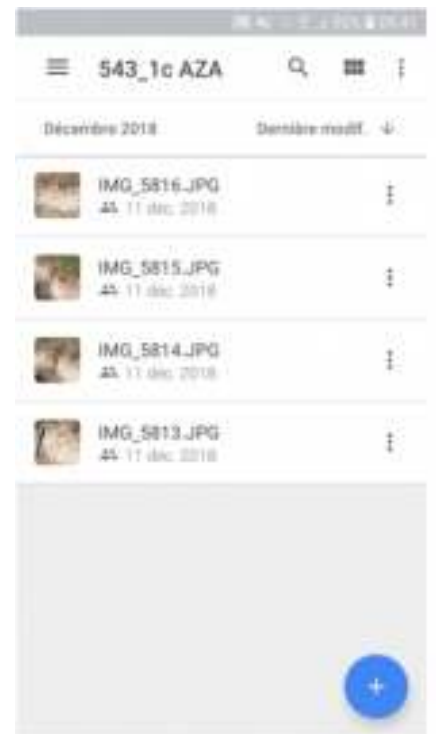

Images produites par les auteurs
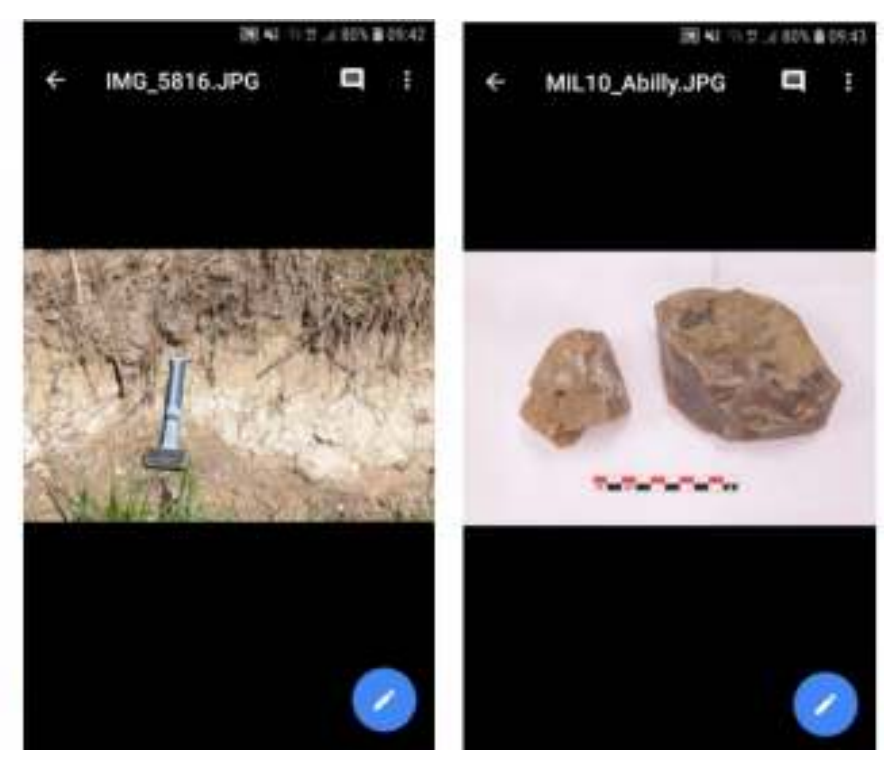

Aujourd'hui, des centaines de jeux de données sur plusieurs régions françaises ont été intégrées dans l'application cartographique. Leur partage et leur mise à jour sont assurés par types et par groupes d'utilisateurs dans le respect des contraintes réglementaires en vigueur concernant la diffusion d'informations publiques. La licence de publication des données est la licence ouverte Etalab 2.0 ${ }^{9}$. Une fois publiées, les données pourront être versées sur des plateformes nationales de diffusion de données ouvertes comme http://geo.data.gouv.fr/fr/. Elles pour- 
ront aussi enrichir la carte archéologique nationale (Fromentin 2019) et l'Atlas des patrimoines du ministère de la Culture ${ }^{10}$, actuellement en refonte.

Enfin, on peut souligner l'intérêt de travaux exploratoires que nous avons pu engager à partir des données sur les formations à silicites par l'utilisation combinée de SIG et de systèmes de modélisation multiagents (Tufféry et al. 2018) ; ces travaux n'auraient pas pu être menés de la même façon avec des méthodes traditionnelles de représentation cartographique.

\section{Les usages de dispositifs numériques pour la production de données archéologiques sur le terrain}

À partir de nos propres parcours et de nos expériences dans le cadre des PCR et du GDR SILEX, nous proposons d'inscrire l'usage de dispositifs numériques pour la production de données archéologiques sur le terrain dans le cadre d'une évolution amorcée voilà près d'une quarantaine d'années.

Avant de parvenir sur les terrains, les premières utilisations de techniques de traitement automatisé de l'information archéologique ont concerné, dans les années 1960, la gestion automatisée de la documentation archéologique. Dans ces usages pionniers, l'archéologue Jean-Claude Gardin a joué un rôle majeur en France et au-delà (Gardin 1991). En partant de ses propres pratiques, il a formulé des interrogations épistémologiques sur les effets de ces techniques documentaires automatisées sur les raisonnements en archéologie et, au-delà, dans les sciences humaines.

Les principaux jalons de l'histoire des dispositifs numériques utilisés sur le terrain en archéologie ont déjà été décrits (Chaillou 2003 ; Desachy 2008). Cette numérisation progressive des pratiques de terrain des archéologues a concerné plusieurs de leurs activités (Giligny et Desachy 2019). Parmi les principaux dispositifs informatisés déployés sur les chantiers archéologiques, on peut citer les tachéomètres " manuels » ou robotisés, les lasers terrestres ou aéroportés, les appareils de géophysique, les divers capteurs photographiques embarqués sur des moyens techniques aéroportés, etc.

À partir du milieu des années 1980 et de l'arrivée de la micro-informatique, plusieurs dispositifs numériques ont été développés. Ils ont concerné l'enregistrement des données descriptives des observations et découvertes archéologiques sur le terrain. En France, le site néolithique des Rivaux (Haute-Loire) est l'un des premiers à avoir bénéficié d'une application de ce type, baptisée Rivalo, dédiée à l'enregistrement des informations provenant des fiches de terrain, dans des fichiers à plat dans l'environnement Apple de l'époque. Au même moment, a été développé sur le chantier école de Lattara, le système Syslat, bien connu des archéologues antiquisants du sud de la France (Bats et al. 1986 ; Py et al. 1991 ; Py 1997) ${ }^{11}$. Syslat est encore aujourd'hui utilisé dans sa version client-serveur Syslat-Serveur. Plusieurs dizaines d'applications ont également été développées au cours des années 2000 et 2010, notamment à l'INRAP dans le cadre de l'archéologie préventive. La plupart ne sont tou- 
tefois utilisables que par leurs concepteurs et développeurs qui sont des archéologues spécialisés en informatique. Les applications ont alors souvent beaucoup de difficultés à être déployées largement parce qu'elles correspondent pour la plupart à des choix qui sont propres à leurs concepteurs, que ce soit à propos des termes utilisés, des modèles de conception de l'enregistrement ou encore des types de contexte archéologique. L'application EDArc (Enregistrement de données archéologiques), développée par l'INRAP depuis 2015, vise précisément à pouvoir être utilisée sur tout type d'opération (diagnostic, fouille, prospection) et de contexte archéologique et elle fonctionne sur ordinateurs, tablettes, smartphones dans les environnements Windows, Android et iOS (Tufféry et Augry 2019). Il en va de même pour l'application concernant la collecte des données pour les formations à silicites développée sous ArcGIS Survey123. En ce sens, plusieurs d'entre nous (V. Delvigne, P. Fernandes, C. Tufféry) sont engagés dans un processus de formation des utilisateurs potentiels, dans le cadre d'écoles thématiques ou de stages de terrain. Ces formations permettent de faire comprendre les tenants et les aboutissants de la démarche d'harmonisation des données, de bien expliquer les processus et les limites pour éviter des incompréhensions et, surtout, d'expliquer en amont comment remplir le formulaire. Ce dernier point est essentiel à une acquisition de données de qualité, il " rassure " les utilisateurs sur le devenir de la donnée et sur leur propre capacité à prendre en main ces nouveaux outils. En parallèle, les retours des utilisateurs ont amélioré l'application qui, en l'espace d'un an et au bout de cinq versions, se présente sous une forme stabilisée.

\section{Les effets des enregistrements nativement numériques des données de terrain}

Les institutions professionnelles de l'archéologie ne cessent de souligner les bénéfices indéniables du numérique pour les processus du cycle de vie des données archéologiques : production, indexation, analyse, partage, diffusion, mise à jour, stockage, archivage pérenne, réutilisation (Pinçon et Sagory 2019 ; INRAP 2018). Pour les silicites, l'application nomade que nous avons développée et la base de données permettent de répondre à ces besoins et autorisent une harmonisation des pratiques ${ }^{12}$ qui ouvre la voie à des traitements nouveaux par la mise en relation des données.

Certains archéologues font d'ailleurs preuve d'un enthousiasme à toute épreuve sur les perspectives qu'offre l'usage des dispositifs numériques pour la discipline :

Grâce aux bases de données, une fois qu'elles ont été correctement remplies et tenues à jour, les archéologues de demain pourront gagner énormément de temps sur la phase de collecte des données documentaires ; ils auront de ce fait le loisir de se consacrer à des interrogations plus générales, donc plus proches de ce qu'attendent d'eux les historiens, les sociologues, les anthropologues et d'une manière générale, les sociétés qui les emploient. [...] Grâce au changement d'échelle apporté par les bases de données, l'évolution actuelle permettrait donc, si elle se confirme, de désenclaver l'archéologie du ghetto (technique, au départ, conceptuel ensuite) dans lequel on l'accuse bien souvent de se cantonner. En allégeant le 
poids des données et des contraintes, la nouvelle gestion des "big data" devrait permettre à l'archéologue de s'ouvrir à des réflexions à la fois plus sûres et plus ambitieuses. (Feugère 2015)

De rares archéologues ont néanmoins pointé la nécessité de faire évoluer la formation pour y inclure des compétences d'ingénierie numérique - les étudiants en archéologie n'étant pas prédisposés à acquérir ces compétences, car majoritairement issus des disciplines littéraires ou, plus largement, des sciences humaines et sociales (Djindjian 2016).

L'inventaire - réalisé par l'un d'entre nous (C. Tufféry) en 2012, puis en 2014 - de plusieurs dizaines d'applications d'enregistrement de terrain utilisées à l'INRAP a montré que la plupart d'entre elles contraignent fortement la saisie des informations descriptives des observations. Ces contraintes se manifestent par l'usage de formulaires de saisie des données qui recourent à des cases à cocher, des listes de valeurs fermées, des formats de données limités, etc. Souvent, ces applications ne permettent pas la réalisation de croquis, alors que beaucoup d'archéologues apprécient de dessiner sur leurs carnets ou leurs fiches sur support papier. Les pratiques de transcription des observations de terrain avec ces applications d'enregistrement sont ainsi profondément modifiées par rapport aux pratiques traditionnelles sur papier (carnets de terrain, classeurs de fouilles, etc.). Ces contraintes expliquent le succès parfois mitigé de ces applications, qui n'emportent pas une adhésion généralisée au-delà de leurs concepteurs-développeurs et du cercle restreint de quelques archéologues rompus aux techniques numériques. Une autre raison de l'adoption limitée de ces outils numériques de saisie est le manque de formation et d'accompagnement dans la mutation des pratiques. Contrairement à ce qu'affirment souvent les promoteurs du numérique, il ne s'agit pas d'un simple changement de support. La matérialité du carnet de terrain ou du journal de fouilles sur support papier permet aux archéologues de s'approprier ces outils, alors que leurs équivalents numériques ne favorisent pas ce processus d'appropriation. Certes, la transcription d'observations sur support papier s'appuie sur des pratiques partagées : usage de certains types de carnets, normes d'écriture, association de textes et de schémas, insertion de collages ou de photos annotées, etc. En cela, l'écriture sur papier n'est pas moins porteuse de pratiques normalisées que ne le sont les outils numériques. Mais les supports traditionnels permettent une relation privilégiée, parfois intime entre l'archéologue et son carnet de terrain, là où les applications numériques sont par principe les mêmes pour un ensemble d'utilisateurs sur un site ou un ensemble de sites.

Le constat de ces différences entre supports traditionnels et numériques de l'enregistrement de terrain a pu être fait à propos de l'application mobile que nous avons développée pour les PCR « Réseau de lithothèques » et le GDR SILEX. Le formulaire d'enregistrement des données de terrain a été fourni aux chercheurs potentiellement concernés sous plusieurs formats : l'application numérique présentée dans le présent article, un fichier de tableur au format XLS, moins contraignant pour la saisie de certaines données, et une version papier. Certains chercheurs préfèrent encore le papier et le trouvent plus adapté à la pratique de terrain, malgré le temps supplémentaire nécessaire et les risques d'erreurs qu'entraîne une saisie numérique ultérieure. Ce constat vaut tout particulièrement pour les données de localisation, où l'on voit des 
erreurs fréquentes dans le choix du système de coordonnées (géographique ou projeté), la notation des valeurs des coordonnées, les unités de distances, etc., alors que l'application mobile enregistre automatiquement les coordonnées des points d'observation sur le terrain dans le système de coordonnées géographiques WGS84, puisque l'application utilise le système de géopositionnement par satellite.

Les effets du numérique ne se limitent pas au passage d'un mode de relation à un autre entre le chercheur et ses supports d'enregistrement. On ne peut pas seulement prendre en considération le gain de temps dans la saisie que permettrait l'enregistrement nativement numérique de données sur le terrain. Ce gain de temps apparent peut en effet masquer une évolution dans les processus de production des observations et de leur intelligibilité. Nombre d'archéologues soulignent la nécessité de pouvoir facilement revenir sur leurs premières observations de terrain. Les premières descriptions ne permettent pas seules de les comprendre, que ce soit pour des structures archéologiques ou du mobilier. Il en est de même pour les sciences d'observation de façon générale. Revenir plusieurs fois sur un même site, sur une même coupe géologique, sur une même structure archéologique, sur un même vestige archéologique est nécessaire à des observations de qualité. Le gain de temps lié à la transcription des observations dans des applications numériques ne peut donc pas suffire à assurer la pertinence ou la véracité des observations. Les supports imprimés traditionnels offrent la possibilité de corriger, compléter, mettre à jour, supprimer la transcription des premières observations de terrain, ce qui est indispensable à la production de connaissances. L'aller-retour entre le chercheur et son carnet de terrain, ses journaux de fouille, ses fiches d'enregistrement, etc., est une condition de possibilité du processus de recherche. En cela, les applications numériques d'enregistrement de terrain doivent garantir au chercheur de pouvoir appliquer la même démarche aisément dans le cycle de vie de ses données de recherche. Cette exigence n'est pas toujours prise en compte par les concepteurs-développeurs de ces applications.

En outre, le temps passé à l'adoption des applications numériques d'enregistrement de terrain peut être important et limiter considérablement, au moins dans les premiers temps, l'équilibre bénéfice-coûts de leur mise en œuvre. La formation, la montée en compétences, la mâ̂trise de toutes les fonctionnalités, le transfert et la sauvegarde des fichiers, leur intégration dans d'autres applications numériques, par exemple, sont des étapes qui demandent du temps. Si les manières de faire des archéologues sont trop fortement modifiées, voire remises en cause profondément du fait de l'usage de dispositifs numériques, on constate souvent que ces dispositifs sont délaissés au profit des supports traditionnels et bien maîtrisés.

Dès lors, on peut légitimement s'interroger sur les avantages annoncés des dispositifs numériques à toutes les étapes des processus de production de connaissances à l'aide de ces dispositifs. Bénéficient-ils véritablement à tous les acteurs de l'archéologie, du terrain à la publication des résultats de la recherche ? Quels sont les gains de scientificité des résultats produits ? Les gains de temps sont-ils vraiment vérifiés pour tous et en toutes circonstances? D’une manière générale, la qualité des résultats s'en trouve-t-elle accrue? 
Ces questionnements dans notre domaine de recherche rejoignent ceux déjà formulés dans d'autres domaines, en particulier dans les sciences sociales (Bourdeloie 2013). C'est le cas des domaines de recherche qui utilisent massivement les logiciels de SIG :

Sur le plan épistémologique, ceci correspond à un glissement dangereux. Sur la base d'une maîtrise technologique, on peut, grâce aux SIG, produire sans grand effort des cartes complexes, qui ont la puissance et la force de conviction des images. Fabriquer une carte est facile, peu coûteux et rapide. La cartographie n'est désormais plus nécessairement l'étape prudente d'une démarche scientifique rigoureuse : elle devient une fin en soi. La dérive de la géographie vers les SIG risque de réduire la discipline [et toutes les disciplines qui utilisent cette technique ?] à une technique de manipulation des données, abandonnant à d'autres le soin (et la responsabilité) de poser les bonnes questions, de construire les bonnes interprétations. (Staszak 2007, 87)

Du fait de cette évolution, l'archéologie s'avance, même si elle ne le revendique encore que très peu, vers le domaine des humanités numériques ${ }^{13}$. À ce titre, l'évolution décrite ici des pratiques de l'enregistrement de terrain et les interrogations qu'elle suscite pourraient être mises en perspective et rejoindre les travaux de collectifs de praticiens des humanités numériques.

\section{Pour un regard distancié sur quelques pratiques numériques en archéologie}

Malgré tout leur intérêt, l'usage généralisé des dispositifs numériques peut entraîner une évolution de la perception par l'archéologue de son terrain d'étude. Par analogie, au milieu du XIX ${ }^{\mathrm{e}}$ siècle, l'usage de la photographie comme mode d'administration de la preuve avait entraîné une évolution dans la relation des archéologues au terrain et aux vestiges archéologiques. Divers auteurs et chercheurs soulignent d'ailleurs certaines formes de dérives liées à l'usage généralisé des techniques numériques dans nos sociétés (Latour 2007 ; Ingold 2010 ; Biagini 2012 ; Sadin 2015 ; Morozov 2015 ; Filippova 2019 ; Calan et Cauchard 2019).

Il semble qu'une part non négligeable des acteurs institutionnels de l'archéologie n'a pas encore pris en compte les impacts de ces changements sur les processus de travail, les dynamiques des organisations ou encore l'accompagnement indispensable dans l'évolution des compétences nécessaires, prenant le risque d'une certaine forme de déni dans ce domaine (Tufféry 2019). À titre d'exemple, si certains archéologues se sont approprié les dispositifs numériques, d'autres en ont délégué l'usage à des membres de leur équipe (topographes, techniciens de fouille, géomaticiens, géophysiciens). En cela, cet usage peut conduire à redéfinir la répartition des tâches de travail au sein des collectifs sur le terrain. Cette évolution concerne essentiellement l'archéologie préventive. En dehors de celle-ci, dans le cas des laboratoires de recherche et des universités, les tâches techniques ont été confiées depuis longtemps aux personnels techniques, les chercheurs se concentrant sur la définition des problèmes de recherche, le choix des sites d'observation... Force est de constater que nombre d'utilisateurs ne sont pas soucieux de comprendre comment fonctionnent ces dispositifs techniques, notamment 
numériques, ni de connaître les algorithmes sur lesquels reposent les modèles des applications numériques dont ils se servent. De ce point de vue, l'exercice de l'esprit critique de chaque chercheur, pris individuellement, tend à diminuer. La prise en compte de la nécessité du travail d'équipe, sur ce point comme sur tant d'autres, joue un rôle central dans notre démarche.

L'intérêt du développement des humanités numériques est précisément de pouvoir répondre au besoin d'interdisciplinarité des savoirs et de mutualisation des savoir-faire autour du numérique. Les enjeux de telles initiatives sont considérables car, dans nos domaines disciplinaires, trop d'archéologues veulent - ou le plus souvent doivent - assurer seuls un ensemble de tâches très diverses (scientifiques, techniques, administratives, gestionnaires, comptables, de recherche de financement, d'animation d'équipes, de communication, de publication, etc.), qui laissent peu de temps pour le développement d'un regard critique sur les pratiques.

Pour plusieurs d'entre nous, des questions épistémologiques se posent face au déploiement des dispositifs numériques. Le numérique en archéologie introduit-il une "rupture épistémologique ", un " seuil de scientificité ", ou n'est-il qu'une étape dans le changement des pratiques amené par l'usage de nouveaux moyens techniques ? Peut-il créer de nouvelles conditions de véridiction en faisant évoluer les critères de vérité de notre époque ? Peut-il faire advenir un nouveau régime de vérité et ouvrir vers une nouvelle dimension anthropologique par la mise en œuvre de nouvelles formes de relations entre des chercheurs et leurs objets de savoirs ou relève-t-il d'une forme de croyance?

Jérémy Huggett souligne que ces dispositifs ne sont pas toujours synonymes de changement de paradigme, contrairement à ce qui est souvent affirmé (Huggett 2020). Tout en étant lui-même adepte de ces dispositifs, cet auteur prône la nécessité de s'interroger sur leurs usages et ce qu'ils impliquent dans la redéfinition des paradigmes et des résultats de la recherche archéologique. Bien évidemment, ces questionnements, rarement évoqués par les promoteurs du numérique sur les terrains archéologiques, ne sont pas des postures technophobes ou technocritiques, ni des appels nostalgiques au retour en arrière. L'objectif est d'interroger des pratiques scientifiques d'un point de vue épistémologique et de les inscrire dans une histoire de la construction des savoirs et des savoir-faire en archéologie. Il s'agit aussi d'une démarche cherchant à remettre la réflexion au cœur des travaux de recherche et à conserver un usage raisonné des outils numériques. Cette recherche reste néanmoins ouverte à des innovations techniques, dès lors que leur usage est justifié et maîtrisé. 


\section{Conclusion et mise en perspective}

Dans notre expérience, le numérique ne constitue pas une révolution scientifique pour l'archéologie. Mais, en accroissant la dimension technique des savoirs et savoir-faire en archéologie à travers les dispositifs sur lesquels ils s'appuient massivement, le numérique pourrait préparer les conditions d'une " crise " de la science archéologique "normale ", pour reprendre la terminologie de Thomas S. Kuhn (1972). Autrement dit, si une " révolution " de l'archéologie devait survenir, ce pourrait être pour dépasser une situation de crise de l'archéologie qui découlerait, d'une part, d'usages insuffisamment raisonnés des dispositifs numériques, d'autre part, d'un niveau plus élevé de "technicisation ${ }^{14}$ " des métiers de l'archéologie, sous la pression en particulier des exigences de l'archéologie préventive et du désir d'une partie des archéologues de rapprocher la discipline des sciences dures. Il est symptomatique que cette forme d'archéologie emprunte, depuis une trentaine d'années, nombre de ses pratiques et de ses normes au secteur du bâtiment et des travaux publics.

Notre volonté d'interroger les pratiques numériques en matière de données spatialisées vient directement de nos pratiques, qui empruntent à des horizons disciplinaires très variés. Travailler ensemble, avec nos spécificités disciplinaires, constitue un enjeu méthodologique majeur pour nos recherches. Mais cela se traduit aussi par des difficultés multiples : échanges des points de vue à rendre compatibles, acceptions de termes à rendre univoques, compétences nouvelles à transmettre d'une façon qui soit compréhensible par tous, résultats à partager et à publier dans un esprit de consensus, etc.

Si les dispositifs techniques mis en place ces quinze dernières années dans le cadre du GDR "SILEX " et des PCR " Réseau de lithothèques " sont incontestablement utiles pour les chercheurs, ils constituent également l'opportunité de porter un regard distancié sur leurs effets (pas encore tous identifiés), sur l'évolution des procédures de travail, sur le partage des données et, de façon plus large, sur la redéfinition de certains des métiers de la recherche en archéologie et dans les disciplines connexes. Réfléchir dans un cadre interdisciplinaire à ces évolutions peut conduire les chercheurs concernés à des exercices de " réflexivité ${ }^{15}$ " sur leurs pratiques numériques. Or, en archéologie, la réflexivité est un exercice auquel la communauté reste peu habituée, surtout en France où l'archéologie processuelle (New Archaeology) a rencontré un écho relativement limité dans les années 1970 et 1980 (Courbin 1982).

Il ne s'agissait de faire, dans cet article, ni le procès ni un éloge inconsidéré du numérique en archéologie, mais de formuler quelques interrogations et pistes de réflexion sur les principes sous-jacents à ces dispositifs et sur leurs effets, en prenant comme exemple la production de données spatiales de terrain ${ }^{16}$. Les divers outils développés et déployés dans le cadre de nos projets ne nécessitaient pas la maîtrise d'un langage informatique. C'est l'un des avantages des solutions techniques utilisées. Mais les possibilités d'adaptation des fonctionnalités et des interfaces des outils proposés ont aussi été contraintes par les solutions 
techniques disponibles. De tels projets supposent donc une formation pour intégrer les clés de compréhension des nouvelles pratiques (limites, processus, finalités), sans pour autant devoir se (trans)former en professionnel de l'informatique (Berra 2012 ; Mounier 2012). C'est dans cette perspective que nous considérons ces projets comme représentatifs des humanités numériques.

\section{Bibliographie}

Allard, Pierre. 2003. « Matières premières, technologie lithique et identité culturelle des populations rubanées du nord-est de la France et de la Belgique ». Thèse de doctorat, université Paris 1.

Allard, Pierre, éd. 2019. " Projet collectif de recherche "Les silicites cénozoïques d'Île-deFrance" ». Rapport d'activité.

Bats, Michel, Jean-Claude Bessac, Lucie Chabal, Claire-Anne De Chazelles, Jean-Luc Fiches, Pierre Poupet et Michel Py. 1986. Enregistrer la fouille archéologique. Le système élaboré pour le site de Lattes (Hérault), Lattes. Lattes : Éditions de l'Association pour la recherche archéologique en Languedoc oriental.

Berra, Aurélien. 2012. "Faire des humanités numériques ». Dans Read/Write Book 2, édité par Pierre Mounier, 25-43. Marseille : OpenEditionPress. http://books.openedition.org/oep/238.

Biagini, Cédric. 2012. L'Emprise numérique. Comment Internet et les nouvelles technologies ont colonisé nos vies. Paris : L'Échappée.

Boule, Marcelin. 1887. "Alluvions anciennes à silex taillés de Malzieu (Lozère) ». Compte rendu de la $16^{e}$ session de l'Association française pour l'avancement des sciences 294-295.

Bourdeloie, Hélène. 2013. « Ce que le numérique fait aux sciences humaines et sociales". TIC \& Société 7 (2). http://doi.org/10.4000/ticetsociete.1500.

Bressy, Céline, éd. 2006. "Réseau de lithothèques en Rhône-Alpes ». Rapport d'activité, projet collectif de recherche. DRAC Rhône-Alpes.

Calan, Jobic (de) et Jérôme Cauchard. 2019. Remède contre l'hystérie numérique. Pourquoi la "révolution digitale» n'est pas une révolution. Paris : Robert Laffont.

Callon, Michel, éd. 1989. La Science et ses réseaux. Genèse et circulation des faits scientifiques. Paris : La Découverte.

Chaillou, Anne. 2003. « Nature, statut et traitements informatisés des données en archéologie : les enjeux des systèmes d'information archéologiques ". Thèse de doctorat de sciences humaines et sociales, université Lumière-Lyon 2. https://tel.archives-ouvertes.fr/tel-00137986/file/TomeI.pdf.

Courbin, Pierre. 1982. Qu'est-ce que l'archéologie ? Paris : Payot.

Delvigne, Vincent. 2016. «Géoressources et expressions technoculturelles dans le sud du Massif central au Paléolithique supérieur : des déterminismes et des choix ». Thèse de doctorat de préhistoire, université Bordeaux 1.

Delvigne, Vincent, éd. 2019. « Projet collectif de recherche "Réseau de lithothèques en Centre Val-de-Loire" ». Rapport d'activité.

Delvigne, Vincent, Paul Fernandes, Christophe Tufféry, Raphaël Angevin, Harold Lethrosne, Thierry Aubry, Marie France Creusillet, Jean Dépont, François-Xavier Le Bourdonnec, Audrey Lafarge, René Liabeuf, Xavier Mangado-Llach, Marie Hélène Moncel, Michel Philippe, Michel Piboule, Jérôme Primault, Jean-Paul Raynal, Clément Recq, Marta Sanchez de la Torre, Gabriel Teurquety et Christian Verjux. 2018. "Grand-Pressigny Was Not Alone : Acquiring and Sharing Data About Raw Materials in the Collective Research Project "Réseau de lithothèques en région Centre-Val de Loire" (France) ». Journal of Lithic Studies 5 (2): " Proceedings of the 11th International Symposium on Knappable Materials, Buenos Aires ». http://doi.org/10.2218/jls.2798.

Delvigne, Vincent, Paul Fernandes, Christophe Tufféry, Jean-Paul Raynal et Laurent Klaric. 2020. «Taphonomic Method and Database to Establish the Origin of Silicites from the Middle-Recent Gravettian of La Picardie Open-Air Site (Indre-et-Loire, France) ». Journal of Archaeological Science : Reports 32 : 102369. https://doi.org/10.1016/j.jasrep.2020.102369. 
Depaepe, Pascal. 2002. « Le Paléolithique moyen de la vallée de la Vanne (Yonne, France) : matières premières, industries lithiques et occupations humaines ». Thèse de doctorat, université Lille 1.

Desachy, Bruno. 2008. « De la formalisation du traitement des données stratigraphiques en archéologie de terrain ». Thèse de doctorat en archéologie, université Paris 1. http://tel. archives-ouvertes.fr/tel-00406241v2.

Detrey, Jean et Thierry Rebmann. 2004. "Exploitation de la matière première lithique dans les marges orientales du massif vosgien au Paléolithique moyen : un gite à Rhyolite dans le vallon du Nideck (France, Bas-Rhin) ". Bulletin de la société préhistorique française 101 (3) : 425-455. https://doi.org/10.3406/bspf.2004.13026.

Djindjian, François. 2016. " Archéologie, de l'analogique au numérique : évolution technique ou révolution méthodologique ?». Les Nouvelles de l'archéologie 146. http://doi.org/10 $.4000 /$ nda.3820.

Fabre, Jacques, Agnès Lamotte et Pierre Antoine. 2002. "La vallée de la Noye ». Rapport $\mathrm{n}^{\mathrm{o}}$ 4, PCR « Géoarchéologie du silex du nord-ouest de la France, lithothèque du bassin-versant de la Somme », DRAC Picardie.

Fabre, Jacques, Agnès Lamotte et Pierre Antoine. 2003. «La vallée de l'Avre ». Rapport $\mathrm{n}^{0}{ }_{5}$. PCR « Géoarchéologie du silex du nord-ouest de la France, lithothèque du bassin-versant de la Somme », DRAC Picardie.

Fernandes, Paul. 2006. « Pétroarchéologie des matériaux siliceux utilisés au Paléolithique moyen dans le sud du Massif central : méthodologie et résultats préliminaires ». Mémoire de diplôme de l'École des hautes études en sciences sociales, École des hautes études en sciences sociales de Toulouse.

Fernandes, Paul. 2012. "Itinéraires et transformations du silex : une pétroarchéologie refondée, application au Paléolithique moyen ». Thèse de doctorat en préhistoire, université Bordeaux 1.

Fernandes, Paul, éd. 2019. Projet collectif de recherche « Réseau de lithothèques en Auvergne-Rhône-Alpes ». Rapport d'activité.

Fernandes, Paul et Jean-Paul Raynal. 2006. "Pétroarchéologie du silex : un retour aux sources ». Comptes rendus Palevol 5 : 829-837. https://doi.org/10.1016/j.crpv.2006.04.002.

Fernandes, Paul et Christophe Tufféry. 2005. «Utilisation d'ArcGIS 9 et d'un SGBD pour la recherche de corrélations spatiales entre sites archéologiques et gites de matériaux siliceux au Paléolithique moyen dans le Massif central ". Communication présentée à Conférence francophone ESRI, Issy-les-Moulineaux, 5-6 octobre, http://www.esrifrance.fr/sig200 5/communications2005/ehess/ehess.htm.

Fernandes Paul, François-Xavier Le Bourdonnec, Jean-Paul Raynal, Gérard Poupeau, Michel Piboule et Marie-Hélène Moncel. 2007. « Origins of Prehistoric Flints : The Neocortex Memory Revealed by Scanning Electron Microscopy ». Comptes Rendus Palevol 6 (8) : 557568. https://doi.org/10.1016/j.crpv.2007.09.015.

Fernandes, Paul, Jean-Paul Raynal, Pascal Tallet, Christophe Tufféry, Michel Piboule, Micheline Séronie-Vivien, Marie-Roger Séronie-Vivien, Alain Turq, André Morala, Jehanne Affolter, Dominique Millet, Françoise Millet, Frédéric Bazile, Patrick Schmidt, Pascal Foucher, Vincent Delvigne, Jérémie Liagre, Stéphane Gaillot, Alexandre Morin, Marie-Hélène Moncel, Jean-François Garnier et Céline Bressy-Léandri. 2013. " Une carte et une base de données pour les formations à silex du sud de la France : un outil pour la pétroarchéologie ». Paléo 24 : 219-228. https://doi.org/10.4000/paleo.2633.

Fernandes, Paul, Christophe Tufféry, Didier Binder, Céline Bressy-Léandri, Jean-Pierre Bracco, Pascal Tallet, André Morala, Alain Turq, Gourguen Davtian, Jean-Baptiste Caverne, Denis Dalphinet, Vincent Delvigne, Jérémie Liagre, Stéphane Gaillot, Dominique Millet, Françoise Millet, Michel Piboule, Régis Picavet, Patrick Schmidt, Antonin Tomasso, Jehanne Affolter, Frédéric Bazile, Jean-François Garnier, Pierre Bintz, Geneviève Pinçon et Jean-Paul Raynal. 2016. "Les formations à silex dans le Sud de la France : élaboration en multipartenariat d'une base de données géoréférencées, premiers résultats ». Dans Ressources lithiques, productions et transferts entre Alpes et Méditerranée, édité par Didier Binder, 137-152. Paris : Société préhistorique française.

Feugère, Michel. 2015. "Les bases de données en archéologie. De la révolution informatique au changement de paradigme ». Cahiers philosophiques 141 (2) : 139-147. http://doi.org /10.3917/caph.141.0139.

Filippova, Diana. 2019. Technopouvoir. Dépolitiser pour mieux régner. Paris : Les Liens qui libèrent. 
Fromentin, Frédérique. 2019. "La carte archéologique nationale ». Culture et recherche $139: 10-11$.

Gardin, Jean-Claude. 1991. Le Calcul et la raison. Essais sur la formalisation du discours savant. Paris : Éditions de l'EHESS.

Giligny, François et Bruno Desachy. 2019. «Informatique et archéologie en France : les années 1980 ». Les Nouvelles de l'archéologie 157-158. http://doi.org/10.4000/nda.7936.

Grégoire, Sophie et Frédéric Bazile. 2005. « La diffusion du silex des Costières du Gard au Paléolithique supérieur ». Comptes rendus Palevol 4 (5) : 413-419. https://doi.org/10.1016/j.c rpv.2005.03.005.

Hewitt, H. Dixon. 1915. "Some Experiments on Patination ». Proceedings of the Prehistoric Society of East Anglia 2 (1) : 45-51. https://doi.org/10.1017/S0958841800023334.

Hue, Edmond. 1929. " Recherches sur la patine des silex ». Bulletin de la Société préhistorique française 26 (9) : 461-468. https://doi.org/10.3406/bspf.1929.12098.

Huet, Briagell. 2006. " De l'influence des matières premières lithiques sur les comportements technoéconomiques au Paléolithique moyen : l'exemple du massif armoricain (France) ". Thèse de doctorat, université Rennes 1.http://tel.archives-ouvertes.fr/tel-0014 7396.

Huet, Briagell, Jean-Louis Monnier, Tanguy Rouxel et Jean-Christophe Sangleboeuf. 2003. «Gestion des matières premières au Paléolithique moyen dans le Massif armoricain : apport de l'étude des propriétés mécaniques des matériaux ". Préhistoire du Sud-Ouest, suppl. 5 ("Les matières premières lithiques en Préhistoire. Inventaire, caractérisation et circulation des matières premières lithiques durant la Préhistoire [Paléolithique, Mésolithique, Néolithique], Actes de la table ronde internationale, Aurillac, 20-22 juin 2002 ") : 199-206.

Huggett, Jeremy. 2020. «Is Big Digital Data Different? Towards a New Archaeological Paradigm ». Journal of Field Archaeology 45 (sup1) : S8-S17. https://doi.org/10.1080/00934690. 2020.1713281.

Ingold, Tim. 2010. « L'outil, l'esprit et la machine : une excursion dans la philosophie de la "technologie" ". Techniques \& Culture 54-55. http://doi.org/10.4000/tc.5004.

INRAP. 2018. Imagerie numérique et $3 D$. Séminaire scientifique et technique organisé par l'INRAP, l'INRIA et l'IRISA. Rennes, juin 2018. https://www.inrap.fr/archeologie-imagerienumerique-et-3d-13628.

Jaccottey, Luc et Annabelle Milleville. 2009. « Gestion des matières premières et implantation humaine autour du massif de la Serre (Jura, France) ». Rapport final. Projet collectif de recherche 2007-2009. https://hal.archives-ouvertes.fr/hal-00482450.

Kuhn, Thomas S. 1972. La Structure des révolutions scientifiques. Paris : Flammarion.

Lamotte, Agnès et Jacques Fabre. 2007. "Approvisionnement et circulation du silex des sites du Paléolithique inférieur de Cagny-la-Garenne, Cagny-l'Épinette et de la Ferme de l'Épinette (Bassin de l'Avre, Somme, France) ». Dans Aires d'approvisionnement en matières premières et aires d'approvisionnement en ressources alimentaires. Approches intégrées des comportements. Actes du XV $V^{e}$ congrès de l'UISPP (Lisbonne, 2006), édité par Marie-Hélène Moncel, Anne-Marie Moigne, Marta Arzarello et Carlo Peretto. Oxford : BAR Publishing

Latour, Bruno. 2007. Reassembling the Social. An Introduction to Actor-Network-Theory. Oxford : Oxford University Press.

Meillet, Antoine. 1866. Recherches chimiques sur la patine des silex taillés. Montauban : Bertuot.

Moncel, Marie-Hélène, éd. 2008. « Site de Payre : Occupations humaines dans la vallée du Rhône à la fin du Pléistocène moyen et au début du Pléistocène supérieur ". Mémoire $n^{0} 46$, Paris : Société préhistorique française.

Morozov, Evgeny. 2015. Le Mirage numérique. Pour une politique du Big Data. Paris : Les Prairies ordinaires.

Mounier, Pierre. 2012. "Qu'apportent les digital humanities ? Quelques exemples », dans Read/Write Book 2, édité par Pierre Mounier, 75-83. Marseille : OpenEditionPress. http://bo oks.openedition.org/oep/247.

Pinçon, Geneviève et Thomas Sagory. 2019. "Les archéologues et le numérique ". Culture et recherche 139 : 45-47. http://www.culture.gouv.fr/content/download/219270/file/Cultureet-Recherche-139_web.pdf?inLanguage=fre-FR. 
Py, Michel. 1997. SYSLAT 3.1. Système d'information archéologique. Lattes : Éditions de l'Association pour la recherche archéologique en Languedoc oriental.

Py, Michel, Joan B. Lopez, Ramo Buxo i Capdevila, Andrès Adroher Auroux, Dominique Garcia, Peter Weidelt et Michel Feugère. 1991. Système d'enregistrement, de gestion et d'exploitation de la documentation issue des fouilles de Lattes. Lattes : Éditions de l'Association pour la recherche archéologique en Languedoc oriental.

Sadin, Éric. 2015. La Vie algorithmique. Critique de la raison numérique. Paris : L'Échappée.

Staszak, Jean-François. 2007. « La géographie ». Dans Épistémologie des sciences sociales, édité par Jean-Michel Berthelot. Paris : PUF.

Thiry, Médard, Paul Fernandes, Anthony Milnes et Jean-Paul Raynal. 2014. " Driving Forces for the Weathering and Alteration of Silica in the Regolith : Implications for Studies of Prehistoric Flint Tools ». Earth Science Reviews 136 : 141-154. http://doi.org/10.1016/j. earscirev.2014.05.008.

Tufféry, Christophe. 2019. "Les compétences numériques en archéologie : un défi majeur et des risques de déni ". ¿ Interrogations ?. http://www.revue-interrogations.org/Les-comp etences-numeriques-en.

Tufféry, Christophe. 2020a. "Ce que le numérique fait à l'archéologie et aux archéologues ». Communication présentée à Atelier DAHLIA (Digital Humanities and Cultural Heritage). Data and Knowledge Management Analysis : extraction et gestion des connaissances (EGC2020), Bruxelles, 28 janvier. http://dahlia.egc.asso.fr/actes_atelier_DAHLIA202 0 .pdf.

Tufféry, Christophe. 202ob. « Ce que le numérique fait à l'archéologie et aux archéologues. Un retour d'expériences et un projet de recherche en cours ». Communication présentée à Congrès 2020 Inforsid (Informatique des organisations et systèmes d'information et de décision). http://inforsid.fr/actes/2020/INFORSID_2020_p3-18.pdf.

Tufféry, Christophe, André Morala, Paul Fernandes et Vincent Delvigne. 2018. « Combinaison d'un SMA et d'un SIG pour aider à la prospection pétroarchéologique. Exploration d'une approche multi-agents dans la modélisation des parcours naturels du silex ». Archéologies numériques 2 (1). http://doi.org/10.21494/ISTE.OP.2018.0276.

Tufféry, Christophe, Paul Fernandes, Vincent Delvigne et Céline Bressy-Léandri. 2019. " Collecte, gestion et valorisation des données sur les formations et les gîtes à silex en France : pour des plateformes cartographiques et de publications partagées ». Archéologies numériques 3 (1) : « Proceedings of the XVIIIth UISPP Congress, Paris, June 2018. Session III-3 (CA), "Construire des référentiels partagés : webmapping et archéologie” ». http://doi. org/10.21494/ISTE.OP.2019.0351.

Tufféry, Christophe et Stéphane Augry. 2019. « Harmonisation de l'acquisition des données d'opérations d'archéologie préventive. Retours d'expériences et perspectives à partir de l'application EDArc ». Communication présentée à Atelier DAHLIA (Digital Humanities and Cultural Heritage). Data and Knowledge Management Analysis, Metz, janvier.

Turq, Alain, Jean-Philippe Faivre, Brad Gravina et Laurence Bourguignon. 2017. « Building Models of Neanderthal Territories from Raw Material Transports in the Aquitaine Basin (Southwestern France) ». Quaternary International 433 : 88-101. https://doi.org/10.1016/j.q uaint.2016.02.062.

Turq, Alain, éd. 2019. " Projet collectif de recherche "Réseau de lithothèques en Nouvelle Aquitaine” ". Rapport d'activité.

\section{Notes}

1 http://infoterre.brgm.fr/formulaire/telechargement-cartes-geologiques-departementales-150-000-bd-charm-50/.

2 Par type gitologique, nous entendons une association d'échantillons qui proviennent du même type de formation (type génétique). Leur composition est fondée sur une série de caractères discriminants, induisant que chaque échantillon à l'intérieur d'un même groupe gitologique possède des caractéristiques oscillant autour d'une moyenne propre à chacune des formations dont il est issu.

3 https://survey123.arcgis.com.

$4 \mathrm{http} / / /$ www.arcgis.com/index.html. 
5 http://www.esrifrance.fr/web-appbuilder-for-arcgis.aspx.

6 Les trois types de cartes scannées disponibles sous forme de flux WMS sont les cartes aux échelles $1 / 1000$ ooo, 1/250 ooo et 1/50 000.

7 http://fr.wikipedia.org/wiki/ISO_15836/.

8 http://www.esrifrance.fr/explorer.aspx.

9 http://www.etalab.gouv.fr/wp-content/uploads/2017/04/ETALAB-Licence-Ouverte-v2. $0 . p d f$.

10 L'Atlas des patrimoines des patrimoines propose l'accès à des informations spatialisées sur les patrimoines : http://www.culture.gouv.fr/Sites-thematiques/Archeologie/Valoriser/Atlas-des-patrimoines/.

$11 \mathrm{http}: / /$ syslat.hypotheses.org/historique-du-projet-syslat/.

12 Le terme d'harmonisation des pratiques est préféré à celui d'homogénéisation qui signifierait l'unification totale des pratiques, alors que l'harmonisation vise leur convergence par le recours aux principes d'interopérabilité technique et sémantique.

13 Celles-ci sont considérées ici comme un ensemble de pratiques (techniques, comportementales, langagières, etc.) liées à l'usage d'équipements informatiques (matériels, logiciels, applications, données, infrastructures) au service de la production, de l'analyse, du stockage, du partage, de la publication, de l'archivage pérenne et de la réutilisation de données concernant les sciences humaines et sociales, seules ou en association avec des données provenant d'autres familles disciplinaires et dans le respect des principes FAIR (findable, accessible, interoperable, reusable).

14 On entend ici par "technicisation " un haut degré d'usage de dispositifs techniques dans les métiers de l'archéologie. Cette technicisation relève de choix faits pour répondre aux exigences des conditions de réalisation des activités de fouille archéologique. Les choix préalables au processus de technicisation sont le fruit d'un travail de " traduction ", c'est-à-dire d'une reformulation des besoins scientifiques en des besoins de gains de temps sur des délais souvent très contraints des opérations d'archéologie préventive. Cette notion de " traduction " consiste à rendre intelligible et admissible la mise en commun d'activités, de procédures, de moyens techniques et d'acteurs qui, initialement, n'ont pas de raison d'être reliés (Callon 1989).

15 On entend ici par " réflexivité " un examen par le chercheur de sa propre démarche scientifique et de ses biais liés à ses divers conditionnements intégrés, plus ou moins conscients, qui sont des valeurs, des hypothèses, des postulats, des présupposés, des normes, dont il s'agit de prendre conscience et de tenter d'interroger. La notion de réflexivité a été proposée pour les sciences sociales, et en particulier en sociologie, par Max Weber et Pierre Bourdieu, qui évoque le terme d'" habitus " pour désigner les divers conditionnements incorporés.

16 L'ensemble de ces interrogations rejoignent celles de la thèse engagée depuis octobre 2019 par l'un d'entre nous, dans le cadre d'une approche épistémologique et d'histoire des savoirs et des savoir-faire en archéologie (Tufféry 2020a, 2020b).

\section{Auteurs}

\section{Christophe Tufféry}

Direction scientifique et technique, INRAP, Paris, France

Géographe, cartographe et archéologue de formation, Christophe Tufféry est ingénieur de recherche à l'INRAP. Spécialisé dans la conception et le développement d'applications numériques pour la saisie de données archéologiques, il participe à plusieurs projets collectifs de recherche Réseaux de lithothèques et au groupement de recherche SILEX. Il réalise actuellement une thèse d'histoire des sciences et d'épistémologie sur les effets du numérique sur l'archéologie et les archéologues.

ORCID 0000-0002-1818-9388

christophe.tuffery@inrap.fr

\section{Vincent Delvigne}

Département de préhistoire, université de Liège, Liège, Belgique

Préhistorien de formation, Vincent Delvigne est actuellement chercheur associé au service de préhistoire de l'université de Liège. Spécialisé en pétroarchéologie et en analyse de 
réseaux et des territoires pour les périodes préhistoriques, il coordonne le projet collectif de recherche Réseau de lithothèques en Centre-Val de Loire et participe au groupement de recherche SILEX.

ORCID 0000-0001-6477-2104

vincent.delvigne@hotmail.fr

\section{Paul Fernandes}

Société Paléotime, Villard-de-Lans, France

Préhistorien de formation, Paul Fernandes travaille actuellement à Paléotime, un opérateur privé d'archéologie préventive. Spécialisé en pétrologie et minéralogie des matériaux siliceux, il coordonne le projet collectif de recherche Réseau de lithothèques en AuvergneRhône-Alpes et participe au groupement de recherche SILEX.

ORCID 0000-0001-6253-8250

paul.fernandes@paleotime.fr

\section{Céline Bressy-Léandri}

Service régional de l'archéologie, DRAC Corse, ministère de la Culture, Ajaccio, France Préhistorienne et archéomètre de formation, Céline Bressy-Léandri est ingénieur de recherche au service régional de l'archéologie de Corse. Spécialisée en archéologie et pétroarchéologie pour la préhistoire, elle coordonne le groupement de recherche SILEX. ORCID 0000-0001-7668-3248

celine.leandri@culture.gouv.fr

\section{Droits d'auteur}

Les contenus de la revue Humanités numériques sont mis à disposition selon les termes de la Licence Creative Commons Attribution 4.0 International. 